\title{
Altruism and Self-interest in a Political Economy of Public Education
}

\author{
Jorge Soares* \\ Portuguese Catholic University \\ and \\ I.G.I.E.R. \\ June 1998
}

\begin{abstract}
The primary objective of this paper is to develop a political economy of public funding of education that accounts for the large disparities observed across countries in the share of GNP allocated to public education.

In a general equilibrium overlapping generations model in which parents care about their children's lifetime utility the rational and forward looking agents vote for a level of public funding of education.

The model mirrors the observed cross-country disparities in the share of GNP allocated to public funding of education. This share increases with per capita income levels as well as with the fertility rate and it decreases with the degree of inequality in the economy. For higher levels of inequality the model can generate a politico-economic equilibrium where private and public investment on education coexist.

In contrast to existing theories the paper does not assume that the factor prices are invariant and I study the importance of the effects of an education policy on the factor prices in the determination of the equilibrium level of this policy.
\end{abstract}

*E-mail: jso@fcee.ucp.pt. I gratefully acknowledge financial support from EC Human Capital Mobility Fellowships Program and from "Ricerca di Base". I thank Thomas Cooley, Elizabeth Caucutt and Nezih Guner for helpful comments on an earlier draft. 


\section{Introduction}

Empirical studies of cross-country differences in public expenditures on education show that they tend to be associated with differences in per capita income levels as well as in the degree of income inequality and in the proportion of school aged children in the population. Existing models which have been used to explore the cross-community differences in education for the US would be unable to match the cross-country pattern. In this paper, I develop a model of the political economy of publicly financed education which has a richer demographic structure and accounts for the impact of the chosen policies on the factor prices. I show that a model with these features is consistent with observed cross-country differences. I also construct a version of this model that is able to describe cross-states differences within a country and I use it for evaluating the welfare implications of a move from a state wide to a nation wide public funding of education decision.

Existing theories of public education typically rely on altruism to account for the existence of public education. In Soares (1996) I show that public investment on education can arise as an equilibrium in a world where individuals are motivated purely out of economic self-interest. In this paper I introduce altruism and show that it increases the equilibrium level of publicly financed education.

I study these issues using a three period lived general equilibrium overlapping generations model where agents care about their children lifetime utility and where both public and private investment on education might coexist.

The first generation agents allocate resources to consumption, to leisure and to the acquisition of human capital, but they cannot borrow against their future income. After the first period of their lives, the agents work for one period and they retire during the third period. During the second period the agents have children whose welfare they value. This leads to transfers that the young agents allocate to consumption and education. Human capital is accumulated through an individual education process represented by a technology which takes as inputs physical resources and the agent's time. As in Soares (1996), I assume that private and public funding of education are considered to be perfect substitutes.

Besides making individual decisions, the agents also take part in a political process through which the public education policies are chosen. With a public education system, the government levies an income tax and uses the revenue to fund education. The agents are rational and forward looking and they vote for the level of taxation. Thus, an equilibrium with publicly funded education must be both a competitive economic equilibrium and a political equilibrium. 
I quantify the theoretical findings by calibrating the parameters of this economy to match some long run features of the US economy. I then compute the equilibrium to determine the level of public funding of education that is chosen by the pivotal voter.

The publicly funded education increases the level of human and physical capital and therefore increases the growth rate of output. The share of income allocated to publicly funded education increases with the level of development of the economy as we observe in the data.

The level of public expenditure on education as a percentage of income is very sensitive to changes in the population growth rate and in the social security policy parameters. The relation between these variables seems to be important in explaining the differences observed across countries with the same level of development. As the share of the young agents in the economy increases, the share of income allocated to public funding of education might increase or decrease depending on the nature of the demographic change. In addition, an increase in the relative size of the social security system results in a decrease in the percentage of income allocated to publicly funded education.

Finally, in this model economy, an increase in intragenerational inequality decreases the political support for public funding of education. This implies a negative correlation between inequality and growth as found in the data.

Fernandez and Rogerson (1994) showed that a move from a community wide to a state wide public funding of education decision can raise the steady-state output and welfare levels. The results in this paper support these findings and they show that a move from a state wide to a nation wide decision level, where the general equilibrium effects are internalized by the voters, further increases the level of income in the economy and the welfare of the agents. The equilibrium tax rate is higher in an economy where the factor prices are flexible; implying that, even though altruism plays a central political role, the complementarity between capital and labor in the production function, and the market incompleteness induce support for a higher level of publicly funded education.

Additionally, the benefits of the general equilibrium effects are bigger in more unequal economies, increasing the benefits from the internalization of those effects by the voters and therefore from the move to a nation wide policy decision level. But, as the degree of inequality increases in the model economy, the richer agents might oppose public funding of education in which cases we will have an equilibrium without public funding of education.

In the next section, I describe the economic environment and the decision 
problems that the agents face. In Section 3, I describe both the economic equilibrium and the political equilibrium concepts employed. Section 4 describes the calibration of the model and section 5 presents the findings for the benchmark economy. Finally, in section 6 , the effect in the politico-economic equilibrium of an increase in the degree of inequality are studied by introducing some intragenerational heterogeneity in the model.

\section{The Economic Environment}

I study an economy where a large number of identical agents are born each period and have a maximum lifetime of three periods facing a probability of surviving each period. The fertility rate of the population is $f$ so that the younger generation is $f$ times bigger than the middle one. The exogenous probability of an agent surviving from age $\mathrm{i}$ to age $\mathrm{i}+1$ is given by $q_{i}$. The number of agents in each cohort relative to the other cohorts is supposed to be stable over time, corresponding to the steady-state age structure of the population. The share of age-i individuals in the population, given by the measure $\mu_{i}, i=1,2,3$ is constant over time and $\mu_{i+1}=\frac{q_{i}}{f q_{2}} \mu_{i}$, with $\sum_{i=1}^{3} \mu_{i}=1$. The population grows at the rate $1+n=f q_{1}$.

The agents in each generation maximize their discounted lifetime utility. For an agent born in period $t$ this is given by

$$
V_{1, t}=\sum_{i=1}^{3} \beta^{i-1} \prod_{j=1}^{i} q_{j} U\left(c_{i, t+i-1}, l_{i, t+i-1}\right)+\beta q_{1} \beta_{a} f V_{1, t+1},
$$

where $\beta$ is the subjective discount factor, $c_{i, t+i-1}$ is consumption and $l_{i, t+i-1}$ is leisure of an age-i individual at period $t+i-1$. The agents are assumed to have children in the second period of their lives and $\beta_{a}$ is the discount factor for their children life-time utility ${ }^{1}$. The weighting of the child's value function by the fertility rate means that the parents care about the welfare of all their descendants. However when the fertility rate, $f$, is not an integer and the agents have "fractions of children" this interpretation is not true anymore as in general the welfare of half a child is not half the welfare of a child. In this case, each parent cares about the average utility of his offspring weighted by the number

\footnotetext{
${ }^{1}$ Among others Altonji, Hayashi and Kotlikoff (1996) reject the hypothesis that intervivos transfers from parents to children are motivated by altruism. They restrict their analysis to adult children, which allows me to assume that there might be an altruistic motivation behind the transfers to dependent childern (non-adult). We will therefore assume that the parents care for their children while they are raising them.
} 
of children. This means that the relative weight of an agent's own utility in his welfare function decreases with the number of children he has.

The "momentary" utility function is assumed to take the constant relative risk aversion form of a Cobb-Douglas consumption-leisure index,

$$
U\left(c_{i, t+i-1}, l_{i, t+i-1}\right)=\frac{\left(c_{i, t+i-1}^{\sigma} l_{i, t+i-1}^{1-\sigma}\right)^{1-\rho}-1}{1-\rho},
$$

where $\rho$ is the coefficient of risk aversion, and $\sigma$ is the coefficient of consumption on the Cobb-Douglas index.

Agents in this economy accumulate claims on real capital used in production by firms, to help smooth consumption across time. The budget constraint facing an individual of age $i$ at time $t$ can be written as

$$
a_{i+1, t+1}=\left(1+r_{t}\left(1-\tau_{t}\right)\right)\left(a_{i, t}-g_{i, t}+b_{i, t}\right)+y_{i, t}-c_{i, t}-e_{i, t}+T_{i, t},
$$

where $y_{i, t}$ is the non-capital income (in terms of the consumption good) of an age-i individual at $t, a_{i, t}$ denotes the beginning-of-period asset holdings of an age$\mathrm{i}$ individual at time $t$, and $r_{t}$ denotes the rate of return on these assets. The variable $e_{t}$ is the physical private investment on education. $\tau_{t}$ is a tax rate on income. Finally, the variables $g_{i, t}$ and $b_{i, t}$ are, respectively the level of assets given by the age-i agent to his children and the level of assets received by the child from his parent and $T_{i, t}$ is a lump-sum transfer received by the agent in period $t$.

Clearly, an agent will not accumulate any assets in the last period of his life so that

$$
a_{4, t}=0, \forall t
$$

Furthermore, I assume that, as usual, the young agents are not able to borrow against future income ${ }^{2}$, therefore imposing the following restrictions:

$$
a_{2, t} \geq 0, \forall t .^{3}
$$

I assume that in the first period the agents can choose the amount of time they will spend learning and how they will allocate their parent's transfers between consumption and education, but they are not allowed to participate in the

\footnotetext{
${ }^{2}$ Credit markets to finance primary and secondary education are almost non-existent and credit markets to finance higher education are also very rare around the world where higher education is mostly publicly funded.

${ }^{3}$ Initially, for computational reasons, I will also assume that the young agents cannot lend. That is they cannot accumulate any physical assets, $a_{2, t}=0, \forall t$.
} 
political process. In the next two periods of their lives agents may vote but will no longer attend school. In the third period they retire. Thus, I distinguish between "children" who cannot vote, workers who are adults below the exogenous mandatory retirement age, and retirees who are above that age.

Furthermore, the young agents are not allowed to work as it is observed in most developed countries. This is not an important assumption as the political economic equilibria with and without this restriction are identical, as in Soares (1996).

Before their mandatory retirement workers decide how much to work, $h_{i, t}$, and earn $w_{t} h_{i, t} s_{i, t}$, where $w_{t}$ and $s_{i, t}$ are the real hourly wage rate per unit of human capital (in terms of the consumption good) and age-i agent's level of human capital in period $t$, respectively. After retirement, the non-capital income of an individual is given by the social security benefits, $s s_{t}$. This amount is computed by taxing labor income at the exogenously given rate $\tau_{s s}$ and distributing the proceeds to the retired agents: $s s_{t} \mu_{3}=\sum_{i} \mu_{i} w_{t} h_{i, t} s_{i, t} \tau_{s s}$. Under these assumptions, the noncapital income of an individual is given by

$$
y_{i, t}= \begin{cases}w_{t} h_{i, t} s_{i, t}\left(1-\tau_{l, t}-\tau_{s s}\right), & \text { for } \mathrm{i}=1,2, \\ s s_{t}, & \text { for } \mathrm{i}=3 .\end{cases}
$$

In this economy, agents are endowed with one unit of time each period that they allocate to work, education and leisure.

The young agents are endowed with a constant level of skills, $s_{1}$. The law of motion of the level of human capital is described by the following process ${ }^{4}$

$$
s_{i+1, t+1}= \begin{cases}s_{1}+\theta d_{1, t}^{\eta_{d}}\left(e_{1, t}+p_{t}\right)^{\eta_{e}}, & \text { for } \mathrm{i}=1, \\ \left(1-\delta_{s}\right) s_{i, t} & \text { otherwise }\end{cases}
$$

where $d_{1, t}$ is the time allocated to education and $e_{1, t}+p_{t}$ represents the total level of physical resources invested on the agent's human capital accumulation, where $e_{1, t}$ and $p_{t}$ are respectively the private and public investment in human capital ${ }^{5}$.

\footnotetext{
${ }^{4}$ This learning technology is similar to the one in Glomm and Ravikumar (1992).

${ }^{5}$ This technology ignores the role of the family background in the returns to education, that is, the level of education of the parents does not affect the human capital accumulation process of the students. This could be achieved for instance by letting the time allocated by the parent to the children's education, weighted by the parent's skill level, be an input in the human capital accumulation function.
} 
The parameters $\eta_{d}$ and $\eta_{e}$ are respectively the coefficients of time and physical resources in the learning technology and $\theta$ is the total factor productivity.

So, the level of human capital accumulated by each individual is an increasing function of the time allocated to learning, $d_{1, t}$, and of the quality of the education service. ${ }^{6}$

The quality of the service provided is assumed to be an increasing function of the physical resources invested on each student's education, $e_{1, t}+p_{t}$.

Public and Private Provision of Education. Public and private provision of education are often seen as mutually exclusive alternatives. The possibility of choosing to acquire education in the private market or in the public sector reduces the likelihood of getting single-peakedness of the preferences over the amount of education that is publicly provided (see Stiglitz, 1974). Because of this, the usual models of majority rule voting may not apply and some problems might raise in terms of the existence of a majority rule equilibrium when voting over the levels of publicly provided education.

Even though public and private provision of education may not be "perfect" substitutes, modeling them as exclusive options is an extreme assumption.

Instead, it seems that the public and private funding of education can be considered supplementary choices ${ }^{7}$. Thus, I assume that the public and private funding of education are perfect substitutes, and I only distinguish the sources of education funding.

The production technology of the economy is described by a constant-returnsto-scale function.

$$
Y_{t}=F\left(K_{t}, L_{t}\right)=\varphi K_{t}^{1-\alpha} L_{t}^{\alpha},
$$

\footnotetext{
${ }^{6}$ The use of expenditure on education as an argument in the learning technology is consistent with Card and Krueger (1992)'s findings. They provide several estimates of the of school quality on the rate of return to education for men born in the United States between 1920 and 1949. They find that men educated in states with high average school quality have a higher return to additional time in school. Hanushek (1986) findings point towards a negative realtion between spending and education output. Somers (1997) explains this latter results by constructing a model that can reproduce positive or negative estimates of the spending-quality relationship even when this relation is positive by construction.

${ }^{7}$ References emphasizing supplementarity can be found among others in Epple and Romano (1996) and Clotfelter (1993).
} 
where $\varphi \geq 0, \alpha \in(0,1)$ is the labor share of output, and $Y_{t}, K_{t}$ and $L_{t}$ are the levels of output, capital input and effective labor input, respectively. The level of capital used by the production sector is equal to the aggregate asset holdings of the agents in the economy or, if the interest rate is given, to the level of capital that clears the factor market. It depreciates at a constant rate $\delta$ and evolves according to the law of motion,

$$
K_{t+1}=(1-\delta) K_{t}+I_{t} .
$$

The effective labor input is given by the number of hours worked by the agents in the economy weighted by their levels of human capital,

$$
L_{t}=N_{t} \sum_{i=1}^{2} \mu_{i, t} s_{i, t} h_{i, t}
$$

where $N_{t}$ is the size of the population in period $t$.

The government in this economy implements the education policy chosen by the agents through voting. Given the selected level of income taxation the government sets the amount of funding so that the education budget is balanced ${ }^{8}$. The constitution does not allow the young agents to vote and the only political decision facing the voters in this economy is to decide on a level of income taxation to finance the education of the young agents. The endogenous level of income taxation is represented by the tax rate on income, $\tau_{t}$. When setting up the tax schedule, the policy makers care only about being elected, and so they maximize the number of votes. As a result, any party in office will follow the same policy and that policy is the one that is voted for by the greatest number of agents.

The social security budget is also assumed to be balanced period by period. The government must implement the social security's labor income tax rate so that its budget is balanced each period.

$$
S S_{t}=\tau_{s s, t} w_{t} L_{t}
$$

where $S S_{t}$ is the level of benefits paid to the current retirees.

Finally, I assume that the government distributes all accidental bequests identically among all the adult agents as a lump-sum transfer described by $T_{i, t}$,

$$
T_{i, t}= \begin{cases}0 & \text { for } \mathrm{i}=1 \\ \frac{\sum_{i=2}^{3}\left(1-q_{i}\right) \mu_{i-1}\left(1+r_{t}\left(1-\tau_{t}\right)\right) a_{i, t}}{\sum_{i=2}^{3} \mu_{i}(1+n)} & \text { otherwise }\end{cases}
$$

\footnotetext{
${ }^{8} \mathrm{I}$ assume that the government only taxes domestic income.
} 


\section{Equilibrium}

In this model the individuals have two roles: they are economic agents that buy goods, accumulate assets, and supply labor, and they are participants in the political process through which policies are determined. I begin by describing the economic decisions given a sequence of political outcome functions. I then describe how the political decisions that determine this sequence are made.

\subsection{Economic Equilibrium}

The economic problem of an age $i$ individual at time $t$ can be written as

$$
\begin{aligned}
V_{i}\left(x_{i}, X ; \Upsilon\right)=\max _{c_{i}, a_{i+1}^{\prime}, h_{i}, d_{i}, e_{i}, g_{i}}\left\{U \left(c_{i},\right.\right. & \left.1-d_{i}-h_{i}\right)+ \\
& \beta q_{i} V_{i+1}\left(x_{i+1}^{\prime}, X_{t+1}^{\prime} ; \Upsilon\right) \\
& \left.+I(i=2) \beta_{a} f V_{1}\left(x_{1}, X ; \Upsilon\right)\right\}
\end{aligned}
$$

s.t.

$$
\begin{aligned}
& a_{i+1}^{\prime}=\left(1+r\left(1-\tau_{k}\right)\right)\left(a_{i}-g_{i}+b_{i}\right)+y_{i}-c_{i}-e_{i}+T_{i}, \\
& s_{i+1}^{\prime}= \begin{cases}s_{i}+\theta d_{i}^{\eta_{d}}\left(e_{i}+p\right)^{\eta_{e}} & \text { for } \mathrm{i}=1, \\
s_{i} & \text { otherwise }\end{cases} \\
& y_{i}= \begin{cases}w_{t} h_{i} s_{i}\left(1-\tau_{l}-\tau_{s s}\right), & \text { for } \mathrm{i}=1,2, \\
s s, & \text { for } \mathrm{i}=3 .\end{cases} \\
& X^{\prime}=X^{\prime}(X ; \Upsilon), \\
& \tau=\Upsilon(X), \\
& V_{4}=0 .
\end{aligned}
$$

where $x_{i}$ and $X$ are vectors describing respectively the individual state of an agent $\left(a_{i}+b_{i}-g_{i}, s_{i}\right)$ and the aggregate state of the economy $(A, S) . A$ and $S$ represent the distributions of physical and human capital across agents. $I$ is an indicator function defined as

$$
I(i=2)= \begin{cases}1 & \text { if } i=2 \\ 0 & \text { otherwise }\end{cases}
$$


$X^{\prime}(X ; \Upsilon)$ is the law of motion of the aggregate state of the economy $X$. $\Upsilon$ is a given political outcome function that determines the level of the tax rate on income in each period. Hence, I am assuming that for each period the level of the tax rate is exogenously given.

A set of decision functions $c_{i}\left(x_{i}, X ; \Upsilon\right), d_{i}\left(x_{i}, X ; \Upsilon\right) e_{i}\left(x_{i}, X ; \Upsilon\right), h_{i}\left(x_{i}, X ; \Upsilon\right)$, $a_{i}^{\prime}\left(x_{i}, X ; \Upsilon\right), g_{i}\left(x_{i}, X ; \Upsilon\right)$; laws of motion $X^{\prime}(X ; \Upsilon)$; and value functions $V_{i}\left(x_{i}, X ; \Upsilon\right)$ are obtained for the current state of the economy $(X)$.

Competitive firms maximize profits, which are equal to $Y_{t}-\delta K_{t}-w_{t} L_{t}-r_{t} K_{t}$, taking the wage, $w_{t}$, and the interest rate, $r_{t}$, as given.

The first-order conditions for the firm's problem determine the following functions for the net real return to capital and the real wage rate:

$$
\begin{aligned}
& R_{t}(X)=(1-\alpha) \varphi\left(\frac{K_{t}}{L_{t}}\right)^{-\alpha}-\delta, \\
& W_{t}(X)=\alpha \varphi\left(\frac{K_{t}}{L_{t}}\right)^{1-\alpha} .
\end{aligned}
$$

\subsection{Political Equilibrium}

I now specify how agents make their political decisions and how the sequence of functions $\Upsilon_{t}$ describing the policies is formed.

\section{Truthful voting:}

In this economy each agent has measure zero. Thus, individual voters do not view their decisions as influencing the aggregate political outcome. In a political environment the best strategy for the agents, if they have some positive probability of being the "pivotal voter", is to act as if they were the "pivotal voter". As there are no strategic gains from misrepresenting their preferences, the dominant strategy when the agents have a positive probability of being the pivotal voter is to vote for their most preferred alternative at every stage of the game.

Consequently, in spite of the outcome being exogenous to each agent, each agent votes as if he were a dictator in the voting period and a "result taker" in the other periods.

\section{Political Choice at the State Level :}

In order to be able to compare a state wide to a nation wide public funding of education decision I assume that a nation can be divided into a finite number of states and the policies of each one of these states have measure zero at the national 
level. That is, the states are such that changes in the state level variables have no effect at the national level. We can think for instance of the federal states in the US or regions from the different countries of the EU.

Therefore, when the political decisions are made at the state level, the voters consider that their choices do not affect the factor prices.

\section{Equilibrium:}

The existence of an equilibrium (or equilibria) where the agents vote for a positive level of publicly financed education has to be confirmed. To determine whether $\Upsilon_{t}(X)$ is an equilibrium political outcome function it is necessary to consider whether the agents have any incentive to deviate and vote for $\tau_{t} \neq \Upsilon_{t}(X)$ at any point in time.

The effects of a policy change can be analyzed by finding the future law of motion of the state variable implied by the responses of agents to the new policy.

The solution to the agents' political problem involves evaluating the utility obtained under the alternative values for the policy parameter, $\tau_{t}$. This requires that the agents can predict the future path of the economy under alternative current policies, which in turn requires the ability to predict the corresponding future policies. Therefore, in general equilibrium agents consider the outcomes of policies that will never be realized, and rationality is maintained in the subgames which would occur in the case of any deviations from the equilibrium path.

The problem of the age-i agent can be formulated in the following way:

$$
\begin{gathered}
\tilde{V}_{i}\left(x_{i}, X, \tau ; \Upsilon\right)=\max _{c_{i}, a_{i+1}^{\prime}, h_{i}, d_{i}, e_{i}, g_{i}}\left\{U\left(c_{i}, 1-d_{i}-h_{i}\right)+\right. \\
\beta q_{i} V_{i+1}\left(x_{i+1}^{\prime}, X^{\prime} ; \Upsilon\right)+ \\
\left.I(i=2) \beta_{a} f \widetilde{V}_{1}\left(x_{1}, X, \tau ; \Upsilon\right)\right\}
\end{gathered}
$$


s.t.

$$
\begin{aligned}
& a_{i+1}^{\prime}=\left(1+r\left(1-\tau_{k}\right)\right)\left(a_{i}-g_{i}+b_{i}\right)+y_{i}-c_{i}-e_{i}+T_{i}, \\
& s_{i+1}^{\prime}= \begin{cases}s_{i}+\theta d_{i}^{\eta_{d}}\left(e_{i}+p\right)^{\eta_{e}} & \text { for } \mathrm{i}=1, \\
s_{i} & \text { otherwise }\end{cases} \\
& y_{i}= \begin{cases}w h_{i} s_{i}\left(1-\tau_{l}-\tau_{s s}\right), & \text { for } \mathrm{i}=1,2 \\
s s, & \text { for } \mathrm{i}=3 .\end{cases} \\
& X^{\prime}=X_{\tau}^{\prime}(X, \tau ; \Upsilon), \\
& \tilde{V}_{4}=0
\end{aligned}
$$

A set of decision functions $c_{\tau i}\left(x_{i}, X, \tau ; \Upsilon\right), e_{\tau i}\left(x_{i}, X, \tau ; \Upsilon\right), d_{\tau i}\left(x_{i}, X, \tau ; \Upsilon\right), h_{\tau i}\left(x_{i}, X, \tau ; \Upsilon\right)$, $a_{\tau i}^{\prime}\left(x_{i}, X, \tau ; \Upsilon\right), g_{i}\left(x_{i}, X ; \Upsilon\right)$; laws of motion $X_{\tau}^{\prime}(X, \tau ; \Upsilon)$; and value functions $\widetilde{V}_{i}\left(x_{i}, X, \tau ; \Upsilon\right)$ are obtained for the current state of the economy $(X)$. Next period's decisions are given by the functions from the individuals' economic problem (3.1).

As agents vote for the education policy parameter $\tau$, they choose from a continuum of possible tax levels; in this context, where there are more than two possible choices, the majority rule might not be a well defined aggregator. Since there is no intragenerational homogeneity and only two generations of agents vote, the majority rule is a well defined aggregator and the pivotal voter is an agent from the biggest generation, the second.

In a model with intragenerational heterogeneity or where there are more than two generations of voters, if preferences over the possible policies are single peaked, the median voter theorem can be used to obtain the aggregated political outcome.

Black's Median Voter Theorem says that, with a majority rule, if the number of agents is odd, there is a unique outcome equal to the best outcome for the individual whose best outcome constitutes the median of the set of best outcomes.

Lemma: Let $\mathrm{m}$ be the generation where the median voter is located, then the aggregate choice will be determined according to:

$$
\tau_{a}(X ; \Upsilon)=\tau_{m}\left(x_{m}, X ; \Upsilon\right)=\arg \max _{\tau} \widetilde{V}_{m}\left(x_{m}, X, \tau ; \Upsilon\right)
$$




\subsection{General Equilibrium}

Definition: A stationary equilibrium is a set of value functions $V_{i}\left(x_{i}, X ; \Upsilon\right)$, $\widetilde{V}_{i}\left(x_{i}, X, \tau ; \Upsilon\right)$; decision rules for consumption and asset holdings $c_{i}\left(x_{i}, X ; \Upsilon\right)$, $c_{\tau i}\left(x_{i}, X, \tau ; \Upsilon\right), e_{i}\left(x_{i}, X ; \Upsilon\right), e_{\tau i}\left(x_{i}, X, \tau ; \Upsilon\right), a_{i}^{\prime}\left(x_{i}, X ; \Upsilon\right), a_{\tau i}^{\prime}\left(x_{i}, X, \tau ; \Upsilon\right), d_{i}\left(x_{i}, X ; \Upsilon\right)$, $d_{\tau i}\left(x_{i}, X, \tau ; \Upsilon\right), h_{i}\left(x_{i}, X ; \Upsilon\right), h_{\tau i}\left(x_{i}, X, \tau ; \Upsilon\right), g_{i}\left(x_{i}, X ; \Upsilon\right), g_{\tau i}\left(x_{i}, X, \tau ; \Upsilon\right) ;$ laws of motion for the distribution of skills and of capital $X^{\prime}(X ; \Upsilon), X_{\tau}^{\prime}(X, \tau ; \Upsilon)$; a pair of relative factor price functions $\{W(X), R(X)\}$; a function for the level of capital per capita $\widehat{K}(A) ;{ }^{9}$ and a political outcome function $\Upsilon(X)$ such that these functions satisfy :

(i) The individual's dynamic programs (3.1) and (3.3).

(ii) The first-order conditions of the firm's problem (3.2).

(iii) Factor markets clear:

$$
\begin{gathered}
\widehat{K}=\frac{1}{1+n} \sum_{i=1}^{3} \mu_{i} a_{i+1}, \\
\widehat{L}=\sum_{i=2}^{3} \mu_{i} s_{i} h_{i} .
\end{gathered}
$$

(iv) The commodity market clears:

$$
\begin{gathered}
\sum_{i} \mu_{i}\left[c_{i}\left(x_{i}, X ; \Upsilon\right)+h_{i}\left(x_{i}, X ; \Upsilon\right)+e_{i}\left(x_{i}, X ; \Upsilon\right)\right]+\mu_{1} p \\
=\widehat{F}(\widehat{K}, \widehat{L})+(1-\delta) \widehat{K}, \\
\sum_{i} \mu_{i}\left[c_{\tau i}\left(x_{i}, X, \tau ; \Upsilon\right)+h_{\tau i}\left(x_{i}, X, \tau ; \Upsilon\right)+e_{i, \tau}\left(x_{i}, X, \tau ; \Upsilon\right)\right]+\mu_{1} p \\
=\widehat{F}(\widehat{K}, \widehat{L})+(1-\delta) \widehat{K} .
\end{gathered}
$$

(v) The laws of motion for the distribution of capital are generated by the decision rules of the agents, which is described by the following vectors:

$$
\begin{gathered}
X^{\prime}(X ; \Upsilon)=\left[a_{i}^{\prime}\left(x_{i}, X ; \Upsilon\right) s_{i}+d_{i}\left(x_{i}, X ; \Upsilon\right)^{\eta_{d}}\left(e_{i}\left(x_{i}, X ; \Upsilon\right)+p\right)^{\eta_{e}}\right]_{i=1,2,3}, \quad(3.10) \\
X_{\tau}^{\prime}(X, \tau ; \Upsilon)=\left[a_{\tau i}^{\prime}\left(x_{i}, X, \tau ; \Upsilon\right) s_{i}+d_{i, \tau}^{\eta_{d}}\left(x_{i}, X, \tau ; \Upsilon\right)\left(e_{i, \tau}\left(x_{i}, X, \tau ; \Upsilon\right)+p\right)^{\eta_{e}}\right]_{i=1,2,3}
\end{gathered}
$$

\footnotetext{
${ }^{9} \mathrm{~A}$ variable with a hat indicates that the variable is expressed in per capita terms.
} 
(vi) The public education system is self financing:

$$
\tau[r \widehat{K}+w \widehat{L}]=\mu_{1} p
$$

as well as the social security system:

$$
\tau_{s s} w=\mu_{3} s s .
$$

(vii) The consumer problems (3.1) and (3.3) are consistent ${ }^{10}$ :

$$
\begin{gathered}
d_{i}\left(x_{i}, X ; \Upsilon\right)=d_{\tau i}\left(x_{i}, X, \Upsilon(X) ; \Upsilon\right), \\
X^{\prime}(X ; \Upsilon)=X_{\tau}^{\prime}(X, \Upsilon(X) ; \Upsilon), \\
V_{i}\left(x_{i}, X ; \Upsilon\right)=\widetilde{V}_{i}\left(x_{i}, X, \Upsilon(X) ; \Upsilon\right), \\
c_{i}\left(x_{i}, X ; \Upsilon\right)=c_{\tau i}\left(x_{i}, X, \Upsilon(X) ; \Upsilon\right), \\
e_{i}\left(x_{i}, X ; \Upsilon\right)=e_{\tau i}\left(x_{i}, X, \Upsilon(X) ; \Upsilon\right), \\
h_{i}\left(x_{i}, X ; \Upsilon\right)=h_{\tau i}\left(x_{i}, X, \Upsilon(X) ; \Upsilon\right) \\
g_{i}\left(x_{i}, X ; \Upsilon\right)=g_{\tau i}\left(x_{i}, X, \Upsilon(X) ; \Upsilon\right) \text { and } \\
a_{i}^{\prime}\left(x_{i}, X ; \Upsilon\right)=a_{\tau i}^{\prime}\left(x_{i}, X, \Upsilon(X) ; \Upsilon\right)
\end{gathered}
$$

(viii) The function $\Upsilon(X)$ is the political outcome:

$$
\Upsilon(X)=\tau_{a}(X ; \Upsilon)
$$

In a small open economy the interest rate is given:

$$
R_{t}(X)=\bar{r},
$$

and the aggregate level of capital will be such that the first order conditions for the firm's problem will be satisfied.

\footnotetext{
${ }^{10}$ That is, the sequence of policy functions $\Upsilon(X)$ is currently generated by the preferences of the agents when the agents take $\Upsilon\left(X^{\prime}\right)$ as the expected equilibrium political outcome for the next period. If the agents believe that the political system described by the sequence $\Upsilon$ will be sustained, then the political outcome for the present period will be the level $\tau=\Upsilon(X)$. Their decision functions will therefore be the same as the ones obtained when the agents take the whole sequence of policy decisions as given, (see problem 3.1).
} 


\subsection{Solving for an Equilibrium}

As explained above, this problem involves evaluating the utility obtained under alternative values for the policy parameter, $\tau_{t}$, which requires that the agents can predict the future path of the economy under alternative current policies, which in turn requires the ability to predict the corresponding future policies. That is, to compute the equilibrium political outcome function, $\Upsilon($.$) , it is necessary to$ know how changes in $\tau_{t}$ will affect the future states of the economy and the future political outcomes $\tau_{t+1}=\Upsilon(X)$. Accordingly, we must compute a fixed point for the function $\Upsilon($.$) .$

Previous work in this area has avoided this problem in two different ways. Some economists assume that agents are myopic voters and therefore do not see this relation between their current political choices and the future political outcomes. Others have chosen to restrict the functional forms of the utility or technology functions and the overall structure of the model in order not to have a relation between the current political decisions and the future political outcome.

I chose not to restrict the model economy a priori and apply an approach similar to the one used in Soares (1996) to solve for the politico-economic equilibrium of the economy. This method is an application to OLG models of the method developed by Krusell and Rios-Rull (1993).

\section{Calibration}

To solve the model numerically I must assign values to the parameters of preferences and technologies. Some parameters are taken from empirical estimates or standard calibrations of similar models; others will be set to fit observations on capital-output ratio, rate of return, transfer levels, hours worked and hours of schooling. I will calibrate the model assuming that the model period is 25 years long. Agents in this model are assumed to be born at the age of 0 and become workers at age 25 , working 25 years and retiring thereafter to a total real-life age of 75 .

\section{Survival Rates:}

I set the probabilities of surviving to be the probabilities of the agents surviving from the middle of the respective age group to the middle of next one using the values from Lee and Carter (1992). 
Table 4.1

\begin{tabular}{|l|l|}
\hline Age group & Probability of Surviving \\
\hline \hline $\mathbf{0}-\mathbf{2 4}$ & $q_{1}=.990947$ \\
\hline $\mathbf{2 5}-\mathbf{5 9}$ & $q_{2}=.946077$ \\
\hline over $\mathbf{6 0}$ & $q_{3}=0$ \\
\hline
\end{tabular}

\section{Fertility Rate:}

In order to have a population growth rate that matches the observed population growth rate for the US economy, I assume that agents can have a non-integer number of children. The exogenous fertility rate is calibrated so that the population growth rate for our model will match the average population growth rate in the US economy in the last decades, .012 (Citibase Data, 1946-1993). For the three generation model this translates to a growth rate of $n=.3475$.

\section{Preferences:}

In the benchmark model I choose the value for the coefficient of risk aversion and the discount factor so that in the politico-economic steady-state the capital-output ratio and the output-consumption ratio are approximately 3 and 1.2 respectively. I set the coefficient of risk aversion $\rho$ equal to 1.3 and I set $\beta$ to be the equivalent in the three generations model of the value (.999). Assuming that agents live for 75 years, this means that $\beta$ will be such that $\beta=.999^{75 / 2}$.

I take the coefficient of consumption in the utility function, $\sigma$, to be .16 , this value implies that on average agents on the labor force allocate a third of their time to market activities.

\section{Altruism:}

To calibrate the rate at which the parents discount the utility of their children I choose $\beta_{a}$ to match the level of transfers from parents to dependent children based on US data. This includes the costs of rearing children. Unfortunately, the literature on child costs is very limited. Bassi and Barnow (1993) compute estimates of parents expenditures on their children and come out with a lower and an upper bound for child costs.

According to the authors, the upper and lower bound estimates of expenditures on children as a share of the family' total expenditures are ${ }^{11}$ :

\footnotetext{
${ }^{11}$ Data from U.S. Consumer Expenditure Survey (CEX)
} 
Table 4.2

\begin{tabular}{|l|l|l|l|}
\hline & \multicolumn{1}{|l|}{ Lower Bound Upper Bound } & Average \\
\hline & $\begin{array}{l}1972-1973 \text { CEX } \\
\text { Rothbart, Lazear } \\
\text { and Michael }\end{array}$ & $\begin{array}{l}\text { 1980-1986 CEX } \\
\text { Engel } \\
\text { and Betson }\end{array}$ & \\
\hline Number of Children: & & & \\
\hline One & 16 & 33 & 24.5 \\
\hline Two & 27 & 49 & 38 \\
\hline Average per Child & 14.33 & 27.33 & 20.83 \\
\hline
\end{tabular}

The altruistic discount factor is set to match the share of the total household expenditures that correspond to expenditures on each child. I chose to match the ratio of each child consumption to the total family consumption in the model $\left(\frac{C_{1}}{C_{2}+f C_{1}}\right)$ to the estimated average shares for the one and two children cases, 20.83. This corresponds to a ratio of expenditures on each child to total household expenditures slightly above the average upper bound share.

\section{Production Technology:}

Following Cooley and Prescott (1995), the share of labor in the production function is set to be .6 . I set the depreciation rate to be $6.4 \%$ on an annual basis, so that the steady-state investment/capital ratio for this economy is $.076^{12}$.

\section{Education Technology:}

I choose parameter values for the education technology such that the steadystate equilibrium of the model matches some observations for the US economy. In particular, I require that the steady-state matches several aggregate, expenditure and time allocation levels. In addition to the usual variables, I have three more decision variables in this model: time allocated to education and private and public funding of education.

Some studies have estimates for the elasticity of the increase in educational attainment with respect to spending per pupil. The range of estimates is very wide and the conclusions from the literature on the evidence of the impact of (public) school quality on learning is mixed (see Card and Krueger, 1994, Betts, 1994, Hanushek, 1986). These values range from -.01716 to .1322 (see Betts, 1994). The elasticity of earnings with respect to spending per pupil ranges from .01 to .29 (see Card and Krueger, 1994). Card and Krueger (1994), survey the

\footnotetext{
${ }^{12}$ The steady-state Investement/Capital ratio in this model economy is equal to the population growth rate plus the depreciation rate.
} 
literature on the economic returns to school quality and they observe that the arithmetic average of 25 estimated elasticities is .16. According to Betts (1994) the results are higher for some studies where a functional form for the education production function similar to the one in this paper is assumed. For instance, for a human capital production function of the type

$$
\frac{\partial s_{t}}{\partial t}=c e_{t}^{\eta}-\delta_{0} s_{t}, \quad 0<\eta_{1}<1
$$

Heckman (1976), estimates $\eta$ to be .67 .

I calibrate the coefficient of expenditures in education in the education production function so that the elasticity of means earnings with respect to per pupil spending on education comes close to .2, as in Fernandez and Rogerson (1994).

Note that in the model's education technology the elasticity of educational attainment to spending per student is given by

$$
\eta_{e} \frac{\theta d_{1, t}^{\eta_{d}} e_{1, t}^{\eta_{e}}}{s_{1}+\theta d_{1, t}^{\eta_{d}} e_{1, t}^{\eta_{e}}}
$$

which, for positive values of the initial level of skills, is inferior to the parameter $\eta_{e}$.

The coefficient of investment in the education process is set to .22 , so that in the final equilibrium the elasticity of educational attainment to spending per student matches the values observed for the US economy. The decreasing returns to the time invested in the learning process mainly reflect the limits to the capacity of individuals to learn.

I target the average hours of time dedicated to education in school. Unfortunately, data on participation in education related activities is scarce. Jorgenson and Fraumeni (1991), calculated the level of school hours per capita for the postwar US economy by assuming that enrolled individuals are in school 1300 hours per year which seems excessive. From NCES (National Center for Education Statistics) data for recent years, the average days of school attended per pupil (primary and secondary school only) in the US is around 161. This number should be higher for higher education students but they also constitute a small share of the student population. I assume that the higher education students attend classes for the average length of the school term which is about 180. So the average attendance rate for a student should be approximately 167.65. If we consider that the average hours in school per day is 7 , we get a total hours per year per enrolled student of 1173.55. The median number of years of education for individuals over 
25 years old is 12.5 , this corresponds to $62.5 \%$ of a students lifetime in our model (4 to 24 years old). So, the amount spent in school per agent of school age is roughly $14.35 \%$ of the available time. ${ }^{13}$

The coefficient in the education process corresponding to the time dedicated to the accumulation of human capital is set to .45 .

The values for the total factor productivities in the production and in the education sector are chosen in order to replicate the US observations for the average level of output per capita in the last decades and attain a reasonable level for the share of GDP allocated to the private funding of education.

\section{Exogenous Political Parameters:}

The level of the social security tax rate is set exogenously to $9.4 \%$ following Halter and Hemming (1987).

The parameter choices are summarized in the following table :

Table 4.3

\begin{tabular}{|c|c|c|c|c|c|c|c|c|c|c|c|c|}
\hline \multicolumn{10}{|c|}{ Benchmark Calibration - 3 Generations } \\
\hline \hline $\mathbf{f}$ & $\boldsymbol{\beta}$ & $\boldsymbol{\rho}$ & $\boldsymbol{\sigma}$ & $\boldsymbol{\beta}_{a}$ & $\mathbf{s}_{\mathbf{1}}$ & $\boldsymbol{\theta}$ & $\boldsymbol{\eta}_{\mathbf{c}}$ & $\boldsymbol{\varphi}$ & $\boldsymbol{\alpha}$ & $\boldsymbol{\delta}$ & $\boldsymbol{\eta}_{\mathbf{d}}$ & $\boldsymbol{\tau}_{\text {ss }}$ \\
\hline 1.3598 & .9753 & 1.3 & .16 & .3 & 1 & 30 & .22 & 10 & .6 & .8086 & .45 & .094 \\
\hline
\end{tabular}

\section{Findings}

\subsection{The Benchmark Calibration}

In order to evaluate the importance of the impact of the education policy on the factor prices in the determination of the politico-economic equilibrium, I compare the closed economy equilibrium with the equilibrium resulting in a small open economy where the factor prices are exogenously given. I present two economies with fixed factor prices, in the first one (open) I set the wage and interest rate to their politico-economic equilibrium levels in the closed economy. In the other one (State) I compute the politico-economic equilibrium levels in the closed economy when the decisions are made at the state wide level, that is I assume that each state's education policy does not affect the factor prices.

\footnotetext{
${ }^{13}$ To obtain the total time devoted to education I should correct this value by the amount of time allocated to human capital accumulation out of school and the leisure time in school.
} 
Table 5.2.1

\begin{tabular}{|c|c|c|c|c|}
\hline \multicolumn{5}{|c|}{ Benchmark I } \\
\hline Equilibrium: & $\boldsymbol{\tau}=\mathbf{0}$ & closed & open & State \\
\hline Tax Rate & $\overline{0}$ & .0824 & .0792 & .0792 \\
\hline Capital & 3.1283 & 3.0896 & 3.0897 & 3.1023 \\
\hline WorkTime & .2979 & .2809 & .281 & .281 \\
\hline$\frac{\text { Parental Transfers }}{\text { Output }}$ & .1444 & .0994 & .0987 & .0997 \\
\hline$\frac{\text { PrivateEd }}{\text { Output }}$ & .044 & 0 & 0 & 0 \\
\hline$\frac{\text { Public. Ed. }}{\text { Output }}$ & 0 & .0742 & .0714 & .0713 \\
\hline Income per Capita & 15.4237 & 15.67 & 15.5373 & 15.5546 \\
\hline Skill Level & 15.1883 & 16.4758 & 16.3098 & 16.3156 \\
\hline Welfare Benefits & & .0969 & .0863 & .09 \\
\hline
\end{tabular}

From a steady-state without public education, the sequence of political and economic choices will lead the economy to a steady-state with public funding of education. The steady-state levels of the policy parameter that maximize the utility level of the second generation agents in the closed economy and in the small open economies are respectively

$$
\tau^{*}=.0824, .0792 \text { and } .0792
$$

These policy parameters are sustainable in steady-state, so they will be political equilibria.

Furthermore, these taxation levels and the corresponding levels of investment on education, $7.42 \% 7.14 \%$ and $7.13 \%$, seem reasonable (see table 5.2.1). In the countries with levels of development similar to the US, educational expenditures have been around $6-7 \%$ of the national product in recent decades.

The table labeled Benchmark I shows the equilibrium average supply of hours of labor, the capital-output ratio and the resources allocated to education in the absence of public funding of education ( $\tau=0$, first column) and for the equilibrium tax rates (other columns). Here we see the reason why the public funding of education has such important general equilibrium effects on the economy: the equilibrium levels of output and of physical and human capital are strictly increasing with the level of public funding of education. The introduction of publicly funded education increases the aggregate per capita levels of these variables and redistributes resources to the current and future workers, bringing up average utility for both the agents alive in the initial period and those not yet born. 
The young agents can allocate the parental transfers to increase both their current and future consumption. They also realize that an additional unit of time spent learning or of investment in education will increase future consumption but at the expense of current consumption (both of leisure and of the consumption good).

As the level of public funding increases, initially the substitution effect will dominate, and the young agents will reallocate time to education, while using more of the parental gifts for current consumption. During this stage, the transfer of time into education increases the productivity of the investment in education and is an extra incentive for the current workers to finance the young agents' education. The increase in the resources available to the young agents is an incentive for the parents that can reduce the amount of transfers to their children. As the wealth effect becomes stronger, the effect on the number of hours devoted to education becomes weaker, and the displacement of resources to private consumption increases. The accumulation of skills will be supported by a higher level of physical investment but a lower level of schooling time.

The effect of the decrease in parental transfers and of the drainage of public resources to private consumption seems to offset the increase in school time, leading to a decrease in the support for higher levels of public education.

In the benchmark equilibrium, altruism plays a central political role as parents vote for the public funding of their children education. As the generation of parents cares about the lifetime utility of their offspring, they want to transfer resources from the adult agents in the economy to their children through the education policy. This will enable the children to accumulate higher levels of human capital while getting a lower level of transfers directly from their parents.

But the equilibrium level of taxation as well as the share of GDP allocated to public funding of education is lower in the small open economies where the factor prices are taken as given. 
Table 5.2.2

\begin{tabular}{|c|r|r|}
\hline \multicolumn{3}{|c|}{ No Altruism } \\
\hline Equilibrium & $\boldsymbol{\tau}=\mathbf{0}$ & \multicolumn{1}{c|}{$\boldsymbol{\tau}^{*}$} \\
\hline Tax Rate & 0 & .0623 \\
\hline Capital & 3.8404 & 3.7452 \\
\hline Output & .2407 & .2405 \\
\hline WorkTime - Adults & .1802 & .1462 \\
\hline WorkTime-Children & .0129 & 0 \\
\hline$\frac{\text { PrivateEd. }}{\text { Output }}$ & 0 & .0548 \\
\hline Public. Ed. & .0804 & .0863 \\
\hline Output & 9.7718 & 13.3055 \\
\hline Education time & 8.3175 & 12.111 \\
\hline Output per Capita
\end{tabular}

As a reference I also computed the steady-state for the economy without altruism and where the young agents are allowed to work in order to finance their consumption and education (see table 5.2.2). In this economy, because of borrowing constraints and the presence of factor complementarities in the production function, agents that are currently accumulating capital support public funding of education as in Soares (1996).

Furthermore, the steady-state level of the policy parameter that maximizes the utility level of the second generation agents in this economy, is .0623 which corresponds to a share of GDP allocated to public funding of education of .0548, which is relatively high when compared to the equilibrium level attained in the presence of altruism. A higher level of publicly funded education would probably be supported in equilibrium if the young agents would allocate more time to their education instead of having to work to finance their consumption.

These results show that in the presence of altruism towards the young agents the general equilibrium effects induced by public investment on education have a strong influence in the determination of the political equilibrium.

The complementarity between capital and labor in the production function, and the market incompleteness are strong enough to motivate support for a higher level of publicly funded education. So, besides the marginal value of public investment on education due to altruism the marginal value stemming from the general equilibrium effects also has to be taken into account.

The complementarity between physical capital and labor implies that when the labor input increases the return on capital also goes up. Therefore, the agents that are currently accumulating capital, the middle-age agents, are also interested 
for selfish reasons in publicly funded education in order to improve the skills of next period's workers. Besides sharing the cost of their children human capital investment with the older generation, the middle-age agents are also offered the opportunity, by voting on the public investment on education, to increase the return on physical capital.

We can better evaluate the importance of the general equilibrium effects looking at their welfare implications. For the same factor prices the change in the level of welfare due to the internalization of the general equilibrium effects by the voters accounts for around $10 \%$ of the increase on welfare from the steady-state without publicly funded education.

But this difference understates the impact of the general equilibrium effects in the equilibrium. In the model the level of benefits are a constant share of the current labor income. For a given wage rate an increase in the level of skills of the future workers will increase labor income increasing therefore the level of benefits of the future retirees and the middle-aged workers will take this effect into account when choosing the education policy. This is a general equilibrium effect of education that is bigger in a closed economy where factor prices are fixed. Furthermore, in reality there is no such connection, or at least it is not as direct, between the level of the social security benefits and the contemporaneous labor income.

Table 5.2.3

\begin{tabular}{|c|r|r|r|r|}
\hline \multicolumn{5}{|c|}{ Benchmark II, $\tau_{\text {ss }}=0$} \\
\hline \hline Equilibrium: & $\boldsymbol{\tau}=\mathbf{0}$ & closed & open & State \\
\hline Tax Rate & 0 & .0903 & .0787 & .0787 \\
\hline$\frac{\text { PrivateEd. }}{\text { Output }}$ & .0489 & 0 & 0 & 0 \\
\hline$\frac{\text { Public. Ed. }}{\text { Output }}$ & 0 & .0794 & .0695 & .0691 \\
\hline Income per Capita & 19.337 & 19.6388 & 19.0151 & 19.0936 \\
\hline Welfare Benefits & & .0821 & .0496 & .0587 \\
\hline
\end{tabular}

In table 5.2.3 I show the equilibria for the model economy without social security. These results show that the way I introduced social security inflates the equilibrium policy level in the economy with constant prices. The change in the level of welfare due to the internalization of the general equilibrium effects by the voters accounts for around $37 \%$ of the increase on welfare from the steady-state without publicly funded education.

In order to make a more accurate evaluation of the impact of the price effects of the education policies in the determination of the political equilibrium I eliminate 
social security from the model.

Fernandez and Rogerson (1994) show that a move from a community wide to a state wide public funding of education decision can raise steady-state welfare level. In their model an education policy financed at the state or national level leads to the reduction of the heterogeneity in the investment in education obtained under the state level policy. This leads to a more equal distribution of income that implies a higher average income for their benchmark calibration. The redistribution of resources and the higher level of expenditures in education resulting in the state choice system offset the benefits from the local choice system that allows the agents to sort themselves across communities according to their preferences.

The results in this paper support these findings. A move from a community wide to a state wide public funding of education decision can raise steady-state welfare level. Although this model economy abstracts from specific features of the community level policy choice models it allows us to study a cause of the welfare improvement that seems to be overlooked in the literature. In fact, in the economy studied, the community level policy choice is equivalent to the private funding of education in the sense that the parents support all the costs of their children education and consumption ${ }^{14}$. When choosing at the state level, the parents will be able to share the cost of their children education with the rest of the economy. The ratio of contributors to beneficiaries increases as the older agents in the economy will also pay taxes to finance education. For a given tax rate more funds will be collected and the pivotal voter will also want a higher tax rate than the one that would be chosen at the community level. The consequent increase in expenditures in education guarantees welfare gains from a move to a state level education policy without the need to resort to the gains from equity that might be obtained under the new system.

Moreover, the results show that a move from a state wide to a nation wide decision level where the general equilibrium effects of the education policy on the factor prices are internalized by the voters further improves the welfare of the agents in the long run but it also increases the level of income in the economy.

\footnotetext{
${ }^{14}$ More precisely, the equilibrium with private funding of education is equivalent to an equilibrium with public funding of education financed with a non-distortionary tax chosen at the community level.
} 


\subsection{Comparative Statics}

I study the response of the equilibrium level of the tax rate to variations in the social security tax rate, the total factor productivities, the population growth rate and the degree of altruism in the following tables.

Again, in order to evaluate the importance of the general equilibrium effects on the politico-economic equilibrium, I compute the equilibrium for the two economies where the factor prices are exogenously given: (open) and (State).

Table 5.2.4

\begin{tabular}{|c|r|r|r|r|}
\hline \multicolumn{6}{|c|}{ Sensitivity Analysis, $\tau_{s s}=.12$} \\
\hline \hline Equilibrium: & $\boldsymbol{\tau}=\mathbf{0}$ & closed & \multicolumn{1}{c|}{ open } & State \\
\hline Tax Rate & 0 & .0801 & .0789 & .0789 \\
\hline PrivateEd. & .0427 & 0 & 0 & 0 \\
\hline Output & 0 & .0725 & .0715 & .0714 \\
\hline Public. Ed. & Output & .101 & .0969 & .0984 \\
\hline Income per Capita & 14.4845 & 14.7167 & 14.6709 & 14.6768 \\
\hline Welfare Benefits & & &
\end{tabular}

An increase in the social security tax rate results in lower equilibrium levels of public funding of education. The wealth effect of the increase in the social security level of benefits reduces the incentives of the young and middle-aged agents to allocate more resources to the human capital accumulation. In particular, due to a larger level of social security benefits and taxes, the middle-aged will be less motivated to transfer resources to the younger agents privately or publicly. The economy with a higher social security tax rate has a lower initial steady-state stock of capital per capita than the benchmark economy and therefore higher interest rates. The increase in the social security tax decreases the return of the public investment on education, decreasing the equilibrium level of the tax rate.

The general equilibrium effects seem to be much less important, but this is mainly due to the social security effect described previously. The impact of education in the future social security benefits through its impact on the effective labor supply almost compensates for the factor prices rigidity.

In the economies where the factor prices are taken as given, the equilibrium tax rates and shares of GDP allocated to public funding of education are higher than the ones in the economy without social security and lower than in the ones in the benchmark economy with social security. 
Table 5.2.5

\begin{tabular}{|c|r|r|r|r|}
\hline \multicolumn{5}{|c|}{ Sensitivity Analysis, $\varphi=20$} \\
\hline \hline Equilibrium: & $\boldsymbol{\tau}=\mathbf{0}$ & \multicolumn{1}{c|}{ closed } & \multicolumn{1}{c|}{ open } & \multicolumn{1}{c|}{ State } \\
\hline Tax Rate & 0 & .0915 & .0799 & .08 \\
\hline$\frac{\text { Private Ed. }}{\text { Output }}$ & .0498 & 0 & 0 & 0 \\
\hline Public. Ed. & 0 & .0805 & .0706 & .0702 \\
\hline Output & 0 & .5304 & 82.813 & 83.1574 \\
\hline Income per Capita & 84.3433 & 85.5304 & .0498 & .059 \\
\hline Welfare Benefits & & .0824 &
\end{tabular}

An increase in the level of the total factor productivity increases the level of publicly funded education as a percentage of income. As the level of income increases so does the investment in capital and human capital. Due to the decreasing returns to spending in education, increasing amounts of public resources need to be allocated to the education process in order to attain higher levels of human capital. Note however that the elasticity of the share of GDP allocated to public funding of education relatively to the level of income is very low.

Table 5.2.6

\begin{tabular}{|c|c|c|c|c|}
\hline \multicolumn{5}{|c|}{ Sensitivity Analysis, $\theta=50$} \\
\hline Equilibrium: & $\tau=\mathbf{0}$ & closed & open & State \\
\hline Tax Rate & $\overline{0}$ & .0925 & .0809 & .0809 \\
\hline$\frac{\text { PrivateEd. }}{\text { Output }}$ & .0504 & 0 & 0 & 0 \\
\hline$\frac{\text { Public. Ed. }}{\text { Output }}$ & 0 & .0813 & .0714 & .071 \\
\hline Income per Capita & 36.6985 & 37.1729 & 35.9916 & 36.1421 \\
\hline Welfare & & .0828 & 0.0499 & .0592 \\
\hline
\end{tabular}

The political equilibrium is very sensitive to changes in the education technology parameters. When the total factor productivity of the education technology increases the rentability of the investment on human capital goes up, and the equilibrium tax rates are higher.

Notice that the difference in the equilibrium share of GDP allocated to public funding of education between the open economy and the closed economy for the benchmark calibration is much bigger than the difference between the open economy in the benchmark calibration and the open economy with the double of the total factor productivity.

Notice that even when the total factor productivity in the production sector doubles the model still does not match the increase in the tax rate or in the share 
of GDP allocated to publicly funded education obtained when the factor prices are endogenous. The same happens when there is an increase the total factor productivity in the education process.

Table 5.2.7

\begin{tabular}{|c|c|c|c|c|}
\hline \multicolumn{5}{|c|}{ Sensitivity Analysis, $n=.4156$} \\
\hline Equilibrium: & $\bar{\tau} \boldsymbol{\tau}=\mathbf{0}$ & closed & open & State \\
\hline Tax Rate & $\overline{0}$ & .0918 & .0825 & .0825 \\
\hline$\frac{\text { PrivateEd. }}{\text { Output }}$ & .0514 & 0 & 0 & 0 \\
\hline$\frac{\text { Public. Ed. }}{\text { Output }}$ & 0 & .0813 & .0733 & .073 \\
\hline Income per Capita & 18.5634 & 18.6688 & 18.2099 & 18.2714 \\
\hline Welfare & & .086 & .0582 & .0666 \\
\hline
\end{tabular}

An increase in the population growth rate increases the equilibrium tax rate and the share of GDP allocated to public funding of eduction. As parents have more children, they will give relatively more importance to the welfare of the younger agents and therefore to public funding of education.

The general equilibrium effects will impact strongly on the valuation of public education increasing the equilibrium tax rate from the fixed prices situation. But the weight of altruism in the agents' behavior increases, and this decreases the gains from the movements in the factor prices.

Table 5.2.8

\begin{tabular}{|c|c|c|c|c|}
\hline \multicolumn{5}{|c|}{ Sensitivity Analysis, $f=1.4286 q_{2}=.9432$} \\
\hline "Equilibrium: & $\tau=\mathbf{0}$ & closed & open & State \\
\hline Tax Rate & $\overline{0}$ & .0897 & .0785 & .0786 \\
\hline$\frac{\text { PrivateEd. }}{\text { Output }}$ & .0488 & 0 & 0 & 0 \\
\hline$\frac{\text { Public. Ed. }}{\text { Output }}$ & $\overline{0}$ & .0789 & .0694 & .069 \\
\hline Income per Capita & 18.3313 & 18.6084 & 18.0378 & 18.1095 \\
\hline Welfare Benefits & & .0826 & .0506 & .0597 \\
\hline
\end{tabular}

An increase in the fertility rate and therefore in the share of students to middle aged has a very small and opposite effect in the share of GDP allocated to public funding of education when the population growth rate stays constant. Because the probability of the children becoming productive adults is lower, the expected return to the investment in human capital is lower.

Therefore, the impact of an increase on the share of young agents in the population on the equilibrium level of the share of GDP allocated to public funding of education strongly depends on the nature of this increase. 
Table 5.2.9

\begin{tabular}{|c|c|c|c|c|}
\hline \multicolumn{5}{|c|}{ Sensitivity Analysis, $\beta_{a}=.4$} \\
\hline "Equilibrium: & $\tau=\mathbf{0}$ & closed & open & State \\
\hline Tax Rate & $\overline{0}$ & .1007 & .1047 & .1047 \\
\hline$\frac{\text { PrivateEd. }}{\text { Output }}$ & .0657 & 0 & 0 & 0 \\
\hline$\frac{\text { Public. Ed. }}{\text { Output }}$ & 0 & .0894 & .0928 & .093 \\
\hline Income per Capita & 22.0324 & 20.8856 & 21.0707 & 21.0394 \\
\hline Welfare Benefits & & .0737 & .0861 & .0806 \\
\hline
\end{tabular}

Increasing the factor at which parents discount their children life-time utility increases the importance of investing on education for purely altruistic reasons. The marginal value of public investment on education due to altruism increases. The optimal tax for the pivotal voter in the small open economies is at a level where the value of the general equilibrium effects is negative. Allowing for these effects will have then a negative impact on the equilibrium level of public funding of education, income per capita and level of welfare.

The model economy can also account for the disparity in public spending on education as a share of output across countries. The model predicts that the share of GDP devoted to formal education increases with per capita income across steady-states with different levels of total factor productivity. This result finds support in the evidence, and is not a feature of other models where publicly funded education is generated by altruism and intragenerational inequalities. In most of these models, the fraction of GDP allocated to public education and per capita income are negatively correlated.

Even though the data shows a positive relation between income per capita and the fraction of GDP allocated to public education, some low income countries allocate to education a share of their GDP comparable to the figures reported for more developed economies.

The relations found in this paper between the fraction of income devoted to public education and factors like the population growth rate, the degree of equity explain the differences observed across countries with the same level of development. The share of income allocated to publicly funded education can increase with the proportion of school aged children in the population as found in the data but it can also decrease depending on the nature of the change in this share. Also, the level of public expenditure on education as a percentage of income is very sensitive to changes in the social security policy parameters. The economies with a higher social security tax rates have lower equilibrium levels of 
the share of income allocated to the public funding of education. But I recall that the relation between social security and the equilibrium level of the share of GDP invested in public funding of education depends strongly on the way I introduced social security in the model.

\section{Intragenerational Heterogeneity}

Most of the models in the public education literature require a certain degree of intragenerational inequality in order to generate support for a positive level of public education. Namely they depend on the median voter being one of the poorest agents in the economy and wanting a higher level of taxation than the average voter would.

In Glomm and Ravikumar (1992, 1994) and in Fernandez and Rogerson (1994), the agents that are poorer prefer a higher level of public funding of education. If the median voter is poorer than the average voter the political outcome will be a positive level of public educations. The only factor that supports public funding of education is the existence of a majority of agents that have incomes below the average and get a net transfer through this policy. The support for public funding of education increases with the distance between median and average income.

Saint-Paul and Verdier (1993) set up an economy where poorer agents prefer more public expenditures on education, therefore the economy will grow faster when the distribution of income is less equitable. As the inequality drops the median voter prefers less taxation and political support for public education decreases.

Given the fixed cost of acquiring education introduced by Perotti (1993) "the lower the pre-tax income of the median voter relative to the average, the higher her preferred tax rate and therefore the share of government expenditure in GDP"

So in these models the more unequal the income distribution is the higher will be the redistributive policy. Income distribution has to be unequal in order to generate some support for public funding of education. ${ }^{15}$

But, in Clarke (1995), Perotti (1996), Alesina and Rodrik (1994) and Persson and Tabellini (1991), the authors show that inequality is negatively correlated with growth and therefore is not a prerequisite for development. ${ }^{16}$

\footnotetext{
${ }^{15}$ In Bertola (1993), Alesina and Rodrik (1994) and Persson and Tabellini (1991), there is also a positive correlation between income inequality and political redistribution.

${ }^{16}$ See Benabou (1996) for a summary of 23 recent studies of the relation between inequality
} 
Also, according to Peter Lindert (1996) "wider inequality in pre-fisc incomes significantly reduces total government spending as a share of GDP" in particular the anti-spending effect of inequality is also reflected in the level of public spending on education. He also claims that "the mean/median income ratio fails to have the positive effect on government spending that the median-voter models predict", referring to Meltzer and Richard (1981), Alesina and Rodrik (1994) and Persson and Tabellini (1991) conclusions. This result also finds support in the work of Perotti (1996) where he found that more equal societies invest more on education.

In Benabou (1996), at low inequality levels, a higher income dispersion implies less redistributive policies, the reverse happening at high levels of income dispersion.

In the model economy, public funding of education appears as an instrument of intergenerational redistribution. The presence of intragenerational inequalities is not a condition necessary for the support of publicly funded education.

In this section, I distinguish the agents of the same generation in two different types to be able to study the relation between public funding of education and intragenerational inequality. In order to obtain equilibria with non-degenerate distributions in this economy inequality is determined by differences in the exogenous parameters. I split each generation in two types of agents and assume that $60 \%$ of each generation's agents are less wealthy than the other ones.

I analyze the effects on the political-economic equilibrium of inequality determined by differences in two exogenous parameters: the initial level of skills of the agents and the total factor productivity in the education process. I focused on these parameters because the effect of differences across agents stemming from talent and how productive are the children in the learning process seemed to be the most relevant for the education choices ${ }^{17}$.

and growth or investement.

${ }^{17}$ The results are robust to changes in the parameters used to introduce inequality in the model. 
Table 6.1

\begin{tabular}{|c|c|c|c|}
\hline \multicolumn{2}{|c|}{ No Public Education Policy } & \multicolumn{2}{|c|}{ shares: $60 \% \quad 40 \%$} \\
\hline Source of Inequality: $s_{1, i}$ & $(.75,1.375)$ & $(.5,1.75)$ & $(.25,2.125)$ \\
\hline Income per Capita & 19.3377 & 19.3398 & 19.3433 \\
\hline \multicolumn{4}{|c|}{ Closed Economy } \\
\hline Tax Rate & .0887 & .0872 & .0857 \\
\hline$\frac{\text { PrivateEd. }}{\text { Output }}$ & 0 & 0 & 0 \\
\hline$\frac{\text { Public. Ed. }}{\text { Output }}$ & .078 & .0766 & .0753 \\
\hline Income per Capita & 19.5715 & 19.505 & 19.4393 \\
\hline Welfare Benefits & .0794 & .0766 & .0736 \\
\hline TypeI & .0478 & .0462 & .0445 \\
\hline TypeII & .0316 & .0304 & .0292 \\
\hline \multicolumn{4}{|c|}{ States } \\
\hline Tax Rate & .0772 & .0756 & .0741 \\
\hline$\frac{\text { PrivateEd }}{\text { Output }}$ & 0 & 0 & 0 \\
\hline$\frac{\text { Public. Ed. }}{\text { Output }}$ & .0677 & .0663 & .065 \\
\hline Income per Capita & 19.0135 & 18.9339 & 18.855 \\
\hline Welfare Benefits & .055 & .0512 & .0472 \\
\hline TypeI & .0328 & .0303 & .0276 \\
\hline TypeII & .0222 & .0209 & .0196 \\
\hline
\end{tabular}


Table 6.2

\begin{tabular}{|c|c|c|c|}
\hline \multicolumn{2}{|c|}{ No Public Education Policy } & \multicolumn{2}{|c|}{ shares: $60 \% 40 \%$} \\
\hline Source of Inequality: $\theta_{i}$ & $(25,37.5)$ & $(20,45)$ & $(15,52.5)$ \\
\hline Income per Capita & 19.4767 & 19.8924 & 20.5897 \\
\hline \multicolumn{4}{|c|}{ Closed Economy } \\
\hline Tax Rate & .0896 & .0885 & 0 \\
\hline$\frac{\text { Private Ed. }}{\text { Output }}$ & 0 & 0 & .0492 \\
\hline$\frac{\text { Public. Ed. }}{\text { Output }}$ & .0787 & .0778 & 0 \\
\hline Income per Capita & 19.6082 & 19.5636 & 20.5898 \\
\hline Welfare Benefits & .0774 & .0521 & 0 \\
\hline TypeI & .0818 & .0988 & 0 \\
\hline TypeII & -.0044 & -.0467 & $\overline{0}$ \\
\hline \multicolumn{4}{|c|}{ States } \\
\hline Tax Rate & .0777 & .0707 & 0 \\
\hline$\frac{\text { Private Ed. }}{\text { Output }}$ & 0 & .0035 & .0492 \\
\hline$\frac{\text { Public. Ed. }}{\text { Output }}$ & .0682 & .062 & 0 \\
\hline Income per Capita & 19.0407 & 19.1372 & 20.5898 \\
\hline Welfare Benefits & .0516 & .0429 & 0 \\
\hline TypeI & .0667 & .0931 & 0 \\
\hline TypeII & -.0151 & -.0502 & $\overline{0}$ \\
\hline
\end{tabular}

The equilibrium level of the share of GDP allocated to publicly funded education decreases with the degree of inequality, as we observe in the data. This is robust to the origin of inequality (I also tried some other parameters with the same qualitative results) and to the level of inequality. As we can see in the tables presented (Tables 6.1 and 6.2), as the spread between the agents increases the equilibrium level of the tax rate and of the share of GDP allocated to education decreases.

The older generation's agents always vote against any positive level of public funding of education. Therefore the median voter will be an agent of the middleaged group that wants the lowest level of publicly funded education.

This result reinforces the importance of several factors on the determination of the political equilibrium. In the one hand the optimal political choice of the agents depends on how much they care about their children and on the productivity of the investment in their children education and also on the level of assets they are accumulating. In the other hand through their political choice the parents can get the older generations to share the costs of their children education. The fact 
that part of the population is poorer (richer) shifts a bigger share of the cost of education towards (away from) them making the investment in public education less (more) productive.

As a result, the median voter can be richer or poorer than the average voter of its generation depending on the relative impact of these factors. But, even if the poorer middle-aged agents want a higher level of public education than the richer ones in order to redistribute resources from the richer agents to their children, they will not be able to implement their wishes. The fact that the retirees do not support public funding of education, in this case, would place the median voter in the richer middle-aged group.

An interesting feature is that, what causes the negative correlation between inequality and growth are the lower levels of government intervention caused by inequality. There is no need to resort to "soak the rich" policies that slow growth and increase with the level of inequality. This of course does not mean that these policies are not important in explaining the observed relation.

This model also generates results supported by the finding of Clarke (1995), Alesina and Rodrik (1994) and Persson and Tabellini (1991). In this economy, education is the motor of economic development, and as the level of inequality increases the support for public funding of education decreases which lowers the level of development of the economy. This generates the negative relation between inequality and growth.

Notice also that from a steady-state without publicly funded education, as the level of public education increases, the degree of inequality decreases.

In the benchmark economy, where the only source of heterogeneity is age, the public funding of education results in a "crowding-out" of private expenditures. In equilibrium private and public education will not coexist; there is no mixed regime. This is clearly counterfactual as we observe both private and public expenditure contributing to the accumulation of human capital. The coexistence of public and private education is obtained in equilibrium in the economy with intragenerational heterogeneity in the distribution of wealth. In fact, for some parameters, when the degree of inequality is high enough in the model economy, the wealthiest agents choose to supplement publicly funded education with private investments in education while the other agents do not invest physical resources on education.

Finally, an increase in the degree of inequality leads to a higher decrease in the share of GDP allocated to public education in an open economy than in the closed economy where the voters internalize in their decisions the movements in 
the factor prices induced by the education policy. When the inequality is bigger also is the impact of these effects in the political equilibrium and on the level of welfare. Therefore, the benefits of a move from a state wide to a nation wide decision level are bigger in more unequal economies as it further increases the level of income in the economy and improves the welfare of the agents in the long run.

Table 6.3

\begin{tabular}{|c|c|c|c|c|}
\hline \multicolumn{3}{|c|}{ Heterogeneous States } & \multicolumn{2}{|c|}{ hares: $60 \% 40 \%$} \\
\hline Source of Inequality: & & & & \\
\hline & 20 & 45 & 25 & 37.5 \\
\hline Tax Rate & .0757 & .0806 & .0776 & .0799 \\
\hline$\frac{\text { PrivateEd. }}{\text { Output }}$ & 0 & 0 & 0 & 0 \\
\hline$\frac{\text { Public. Ed. }}{\text { Output }}$ & .0666 & .0707 & .0681 & .07 \\
\hline Income per Capita & 11.6103 & 31.6798 & 15.2454 & 25.2083 \\
\hline Welfare Benefits & .0209 & .0204 & .0207 & .0205 \\
\hline per total output & .0123 & .0331 & .0164 & .0269 \\
\hline
\end{tabular}

If there is inequality across states then there will also be gains from equity associated with the political choice at the national level (see Table 6.3). A policy chosen at the national level implies a higher level of income per capita and higher level of welfare per capita in the steady-state. These gains are due to the redistribution of resources from states with a lower return to the investment in education, the richer states, to states with a higher return.

The intuition behind this result is similar to the one described by Fernandez and Rogerson (1994) but at an aggregate level. Parents in poorer states invest less in their children's education. Given the decreasing marginal productivity of the expenditures on human capital, these children will have a higher return to their investment in education. There is therefore an efficiency gain from channeling resources from the wealthier states with lower returns to their investment in human capital to the poorer states with higher returns.

This result is robust to the source of inequality and only fails when the difference across states is caused by large disparities in the education process. If the difference across states in the education technology parameters $\left(\theta, \eta_{e}, \eta_{d}\right)$ is high it is possible that the difference in the levels of investment is not high enough to offset the structural differences in the return to education, and then it is not efficient to redistribute resources across states. For instance, when the disparity in the total factor productivity of the education process is high, the differences 
in the levels of investment in education might not be big enough to overcome the difference in $\theta$ and bring the return to education in the poorer states to a level above the return to education in the wealthier states.

This would be true for the political choices of the poorer middle-aged voter. But what actually happens is that as the difference in the capability of accumulating human capital increases between the two groups of agents, the education policy will imply an higher level of intragenerational redistribution. The richer agents will be less willing to transfer resources to the poor agents as their gains from the intergenerational redistribution will be relatively lower. Beyond certain levels of inequality (for example $\theta_{1}=15, \theta_{2}=52.5$ ) the richer parents will also oppose public funding of education and we will have equilibria where there is only private education (or public education at the community level).

These large disparities in the education process across states can stem from differences in the levels of human capital of the older generations. If we assume that another factor in the human capital accumulation process is the time the parents allocate to their children's education weighted by their human capital level, the offspring of more educated agents have a higher return to education. It might then be more efficient to let states with highly (un)educated genitors choose their education policies independently.

Table 6.4

\begin{tabular}{|c|r|r|}
\hline Heterogeneous States & \multicolumn{2}{c|}{ shares: $\mathbf{6 0 \%} \mathbf{4 0 \%}$} \\
\hline Source of Inequality: & \multicolumn{2}{|c|}{$\theta_{i}$} \\
\hline & 15 & 52.5 \\
\hline Tax Rate & .0726 & .081 \\
\hline PrivateEd. & 0 & 0 \\
\hline Output & .0639 & .0711 \\
\hline Public. Ed. & 8.2266 & 38.4631 \\
\hline Output & .0211 & .0204 \\
\hline Income per Capita & .0084 & .0388 \\
\hline pelfare Benefits &
\end{tabular}

Some questions arise when the policy decisions are made at the state level: what happens when agents are allowed to move across states? How will the migration of the older agents to states with a lower tax rate affect the equilibrium? Will agents from poorer states migrate to wealthier states so that their offspring will take advantage of the higher public investment in physical capital? The possibility of the agents "voting with their feet" is important in this setting and 
might reduce dramatically the benefits from opting for a state level decision when there are heterogeneous states, reinforcing the benefits of a nation wide choice of the level of public resources to allocate to education.

\section{Alternative Financing Instruments}

Thus far, the fiscal instrument used to finance education is a tax on income. I started with this assumption to replicate a type of taxation that does not discriminate across sources of income and levies an identical tax rate on labor and capital incomes. But this fiscal policy is highly distorting, mainly because it taxes capital. In this section I analyze the effects on the politico economic equilibrium of the use of less distorting types of taxation, namely I study the financing of education through the taxation of labor income and of consumption.

A tax on consumption in this framework does not remove the distortions in the physical capital accumulation, but it reduces those distortions. In fact the parents will have a higher incentive to increase leisure and to transfer resources to their children instead of accumulating capital or consuming, so that they can invest more on education. However, in the politico-economic equilibrium, there is no private investment on education and therefore this distortion is also removed or, more precisely, is "transferred" to the political choice of the agents. The lower level of distortions imply that the same revenue can generate a higher level of welfare and income. Furthermore, because the older generations have higher marginal propensities to consume, resorting to this type of taxation enables the parents to transfer a higher share of the cost of the investment in education to the elderly.

Finally, as this tax rate is less distorting, the increase in the support for public education generated by the general equilibrium effects is reflected in a bigger increase of the level of income and welfare per capita. In this case a policy choice at the national level becomes even more attractive than the policy choice at the state level. 
Table 7.1

\begin{tabular}{|c|r|r|r|r|}
\hline \multicolumn{5}{|c|}{ Consumption Tax } \\
\hline \hline Equilibrium: & $\boldsymbol{\tau}=\mathbf{0}$ & closed & open & State \\
\hline Tax Rate & 0 & .1519 & .1354 & .1354 \\
\hline$\frac{\text { PrivateEd. }}{\text { Output }}$ & .0489 & 0 & 0 & 0 \\
\hline$\frac{\text { Pubic. Ed. }}{\text { Output }}$ & 0 & .1068 & .0966 & .0966 \\
\hline Income per Capita & 19.337 & 22.7733 & 22.1634 & 22.1634 \\
\hline Welfare & 1.227 & 1.3373 & 1.3287 & 1.3288 \\
\hline
\end{tabular}

The taxation of labor income will distort the choices of the agents away from labor and also from the accumulation of human capital as the return to this investment is directly related to labor income. The problem with this type of tax is that in our three generations model it only taxes the second generation that are not able then to share the cost of their children education through a public education policy. In this case and given the distortions introduced by the tax the politico-economic outcome in an economy with fixed factor prices is an equilibrium without public funding of education. Surprisingly, when the agents make their policy decisions in an environment with flexible prices a positive level of public funding of education will be supported in equilibrium. This is due to the increase in the future aggregate labor supply resulting from public funding of education that implies an increase in the return to the agents' investment in capital. In fact the public investment on education not only increases the amount of human capital accumulated by an agent's children but it also increases the level of human capital accumulated by all children and therefore the aggregate level of human capital. The resulting benefits are strong enough to compensate for the decrease in net labor income.

Table 7.2

\begin{tabular}{|c|r|r|}
\hline \multicolumn{3}{|c|}{ Labor Tax } \\
\hline \hline Equilibrium: & $\boldsymbol{\tau}=\mathbf{0}$ & closed \\
\hline Tax Rate & 0 & .0922 \\
\hline$\frac{\text { Private Ed. }}{\text { Output }}$ & .0489 & 0 \\
\hline Public. Ed. & 0 & .0553 \\
\hline Output & 19.337 & 17.7336 \\
\hline Income per Capita & 1.227 & 1.2086 \\
\hline Welfare &
\end{tabular}




\section{Final Comments}

The constructed economy mirrors the cross-country empirical facts on public funding of education. The share of GDP allocated to public spending on education increases with the level of development and the fertility rate. Furthermore, in this model an increase in intragenerational inequality decreases the political support for public funding of education, which is empirically supported, and this implies a negative correlation between inequality and growth as found in the data.

In this paper, I also show that in the presence of altruism towards the young agents the general equilibrium effects induced by public investment on education have a strong impact on the politico-economic equilibria. The equilibrium tax rate is higher in the economies where the factor prices are fixed implying that the complementarity between capital and labor in the production function motivates support for a higher level of publicly funded education.

This analysis is useful in comparing the implementation of a political choice of publicly funded education at a national level where factor prices are flexible instead of at a state or community level where factor prices would be taken as given.

Fernandez and Rogerson (1994) showed that a move from a community wide to a state wide public funding of education decision can raise steady-state output level. The results in this paper support these findings and show that a move from a state wide to a nation wide decision level where the general equilibrium effects are internalized by the voters further increases the level of income and the welfare of the agents in the economy. Additionally, the benefits of the general equilibrium effects are bigger in more unequal economies, increasing the gains from expanding the level at which education policies are decided.

Finally, I would like to mention the importance of the relation between fertility and education decisions. In this paper, I studied the public and private education decisions taking as given the fertility rate of the economy. I then analyzed how the politico-economic equilibrium changed with changes in the fertility rate. Perotti (1996) shows that fertility is negatively correlated with growth and positively correlated with inequality. Richer countries have a lower fertility and higher investment in human capital. This can be related to a higher return on the investment in human capital and a higher opportunity cost of raising children. The same thing happens within countries with richer agents. A redistribution through public funding of education can increase the investment in human capital. 


\section{References}

[1] Altonji, J. G., Hayashi, F. and Kotlikoff, L. J. (1996) "Parental Altruism and Inter Vivos Transfers: Theory and Evidence", Mimeo.

[2] Alesina, P. and Rodrik, D. (1994) "Distributive Politics and Economic Growth", Quaterly Journal of Economics, 109, 465-490.

[3] Bassi, L. J. and Barnow B. S. (1993), "Expenditures on Children and Child Support Guidelines", Journal of Policy Analysis and Management, Vol.12, N. 3, 478-497.

[4] Benabou, R. (1996) "Inequality and Growth," NBER Macro Annual.

[5] Bertola, G. (1993) "Factor Shares and Savings in Endogenous Growth" American Economic Review, 83, 1184-1198.

[6] Boldrin, M. (1993) "Public Education and Capital Accumulation", Discussion Paper 9301 Centro de Investigacion Economica, I.T.A.M..

[7] Card, D. and Krueger, A. (1994), "The Economic Return to School Quality: A Partial Survey". Industrial Relations Section. Princeton University. Working paper \#334.

[8] Cooley, T. and Prescott, E. (1995), "Economic Growth and Business Cycles." Frontiers of Business Cycle Research, Ed. Thomas F. Cooley. Princeton University Press

[9] Clarke, G. (1995) "More Evidence on Income Distribution and Growth,"

[10] Clotfelter, C. (1993). "The Private Life of Public Economics". Southern Economic Journal, 59, 579-596.

[11] Cukierman, A. and Meltzer, A. H. (1989) "A Political Theory of Government Debt and Deficits in a Neo-Ricardian Framework". American Economic Review, vol. 79, no. 4, 713-732.

[12] Epple, D. and Romano, R. (1996). "Public provision of Private Goods". Journal of Political Economy, vol. 104, no.1, 57-84. 
[13] Epple, D. and Romano, R. (1995). "Ends Against the Middle: Determining Public Service Provision When There Are Private Alternatives". Forthcoming Journal of Public Economics.

[14] Fernandez, R. and Rogerson, R. (1994). "Public Education and Income Distribution: A Quantitative Evaluation of Education Finance Reform", Working Paper n. 4883, NBER.

[15] Glomm, G. and Ravikumar, B. (1994-a). "Vouchers, Public and Private Education, and Income Distribution", Mimeo.

[16] Glomm, G. and Ravikumar, B. (1994-b). "Opting Out of Publicly Provided Services: A Majority Voting Result", Social Choice and Welfare, forthcoming.

[17] Glomm, G. and Ravikumar, B. (1992). "Public versus Private Investment in Human Capital: Endogenous Growth and Income Inequality", Journal Of Political Economy, 1992, vol. 100, n.4, pp 818-834.

[18] Hanushek, E. A. (1986). "The Economics of Schooling: Production and Efficiency in Public Schools." Journal of Economic Literature 24 (September), 11141-1177.

[19] Halter and Hemming (1987). "The Impact of Demographic Change on Social Security Financing". I.M.F. staff Papers 34, no 3, 471-502.

[20] Heckman, J. J. (1976). "Estimates of a Human Capital Production Function Embedded in a Life-Cycle Model of Labor Supply", Household Production and Consumption, Ed. Terleckyj, N.B.E.R.

[21] Imrohoroglu, A., Imrohoroglu, S. and Douglas J. (1994). "A Life Cycle Analysis of Social Security". Mimeo. Economic Theory. Forthcoming.

[22] James, E. (199?). "Why do Different Countries Choose a Different PublicPrivate Mix of Educational Services?". The Journal Of Human Resources. 571-592.

[23] Jorgenson, D. W., Fraumeni, B. M. (1991). "The Output of the Education Sector", Discussion Paper \#1542, Harvard Institute Of Economic Research. 
[24] Krusell, P. and Rios-Rull, J. (1992). "Vested Interest in a Positive Theory of Stagnation and Growth". Mimeo. Univ. Pennsylvania.

[25] Krusell, P. and Rios-Rull, J. (1993). "Politico-economic Equilibrium with Growth". Journal of Economic, Dynamics and Control, forthcoming, special issue edited by L. Jones and R. Manuelli.

[26] Lee, R. D. and Carter, L. R. (1992) "Modeling and Forecasting US Mortality", Journal of the American Statistical Association, September 1992, Vol.87, No. 419.

[27] Lindert, P. H. (1996) "What Limits Social Spending?", Explorations In Economic History, 33, 1-34.

[28] Meltzer, A. H. and Richard, S. F. (1981). "A Rational Theory of the Size of Government". Journal of Political Economy, vol. 89, pp 914-927.

[29] Perotti, R. (1996) "Growth Income Distribution and Democracy: What the Data Say." Journal of Economic Growth, 1, 149-187.

[30] Persson, T. and Tabellini, G. (1991) "Is Inequality Harmful for Growth? Theory and Evidence," American Economic Review, 48, 600-621.

[31] Soares, J. (1996). "The Political Economy of Public Education", I.G.I.E.R. Working Paper n.106.

[32] Somers, J. (1997). "Reconciling Rational Household Behavior with Estimated Education Production-Functions". Mimeo, University of Rochester.

[33] Stiglitz, J. (1974). "The Demand for education in Public and Private School systems", Journal of Public Economics 3.

[34] Rios-Rull, J. V., "Life-Cycle Economies and Aggregate Fluctuations," Mimeo. Carnegie Mellon University, 1992.

[35] Rios-Rull, J. V., "Working in the Market, Working at Home, and the Acquisition of Skills: A General-Equilibrium Approach," American Economic Review, September 1993, 893-907.

[36] Saint-Paul, G. and Verdier, T. (1993) "Education, Democracy and Growth," Journal of Development Economics, 42,2, 399-407. 
[37] ...... 